\title{
Necessidades de capacitação e aperfei çoamento dos profissionais de Equipes de Saúde da Família da 4⿳a Coordenadoria Regional de Saúde do Estado do Rio Grande do Sul
}

\author{
Necessities of professionals of the Family Health Teams from the \\ "4a Coordenadoria Regional de Saúde do Estado do Rio Grande \\ do Sul" for training and improvement
}

M aria Evanir Vicente Ferreira ${ }^{1}$

M aria Denise Schimith ${ }^{1}$

Nilton Carlos Cáceres ${ }^{3}$

${ }^{1}$ Universidade Estadual de Londrina. Av. Robert Koch 60 , Vila O perária. 86000-000 Londrina PR. mariaevanirvf@gmail.com ${ }^{2}$ UniversidadeFederal de Santa M aria.

${ }^{3}$ Universidade Federal de Santa M aria, Centro de Ciências Naturais e Exatas, Departamento deBiologia.
Abstract This study had the aim to verify the necessities of training and improvement of the $4^{\text {th }}$ Regional Coordination in Health of Rio Grande do Sul State family health teams. The data collection was carried out through the application of questionnaires with objective questions, composed by two parts: field and competence nucleus. For data analyses, N ormality, Chi-Square and G tests were used as statistical procedures for Easy and Difficult attributions indicated by the professionals. Professionals have shown less difficulty with generic attributions, related with basic methods and techniques of each health area. H owever, they have revealed a lot of difficulties with attributions relating to the search of new partners in health insidecommunities, stimulation of the peopleparticipation in the discussion of health rights, and completion of theSIA/SIAB forms, and others. Even after 12 years of the foundation of the Family $\mathrm{H}$ ealth Program (PSF), several difficulties are still observed concerning the way to work with this new health strategy in Brazil. Proposals are made for the complete understanding and improvement of the PSF strategy.

Key words Health Family Program, Human resource formation, Competence field, Competence nucleus, Responsibilities
Resumo Este estudo objetivou verificar as necessidades para a capacitação e aperfeiçoamento dos profissionais das equipes de saúde da família dos 31 municípios que compõe a 4aㅡ Coordenadoria Regional de Saúde do Estado do Rio Grande do Sul. A coleta dedadosfoi realizada através da aplicação de um questionário com questões objetivas, composto de duas partes: campo e núcleo de competências. Para análise dos dados obtidos, foram utilizados testes de normalidade, qui-quadrado e teste $G$ para as atribuições fáceis e difíceis indicadas pelos profissionais. Os profissionais mostraram menores dificuldades com atribuições genéricas, relacionadas a métodos e técnicas básicas de cada área de formação. Porém, revelaram dificuldades tais como a busca de parcerias nas comunidades, estimulação da partici pação popular na discussão sobre direitos à saúde e o preenchimento dos formulários do SIA/SIAB. M esmo após doze anos da criação do Programa deSaúde da Família (PSF), observam-se ainda várias dificuldades em atuar de forma adequada e necessária a este novo model o detrabalho em saúde. São propostas medidas que visam auxiliar e consolidar o PSF em seus diversos níveis.

Palavras-chave Saúde da família, Formação de recursos humanos, Campo de competências, Núcleo de competências, Responsabilidades 
Introdução

O Programa de Saúde da Família (PSF) é uma das grandes prioridades do M inistério da Saúde. Ele surge como uma estratégia de reorganização do modelo assistencial em saúde e consolidação do Sistema Ú nico de Saúde. As equipes são compostas minimamente por um médico generalista, um enfermeiro, um auxiliar de enfermagem e de quatro a seis agentes comunitários de saúde. A partir de 2001, profissionais de saúde bucal passaram a fazer parte das equipes básicas (odontólogo, técnico dehigiene dental eauxiliar deconsultório dentário). Outros profissionais podem se integrar à equipe, de acordo com especificidades locais. 0 foco deste programa é a família no seu espaço físico esocial, proporcionando à equipe de saúde uma visão ampliada do processo saúde-doença, que permite intervenções além das práticas curativas ${ }^{1}$.

O perfil ea atuação dos profissionais de saúde deste programa são os principais fatores de sucesso para o resultado positivo do trabalho das equipes de saúde da família. Esse novo modelo exige profissionais com visão sistêmica e integral do indivíduo/família e comunidade onde os mesmos estão inseridos. Estes profissionais devem ser capazes de atuar com criatividade e senso crítico, mediante uma prática humanizada e resolutiva queenvolva ações de promoção, prevenção, recuperação e reabilitação da saúde. Também devem planejar, organizar, desenvolver eavaliar ações que respondam às necessidades da comunidade atendida, articulando os diversos setores envolvidos na promoção de saúde. E para que isso aconteça, devem interagir com a comunidade, mobilizando-a e estimulando sua participação $0^{1,2}$.

O profissional de saúde da família deve ter habilidades nas clínicas de relacionamento, de desenvolvimento do trabal ho em equipe, de estabelecimento de parcerias, de comprometimento com o usuário e de respeito individual e familiar quanto ao modo de adoecer ou ter saúde. Também serve de fonte de recursos para uma população definida no que concerneà prevenção etratamento de agravos e doenças. Tem capacidade de manejar as situações adversas, seja no acesso às ações da atenção básica de saúde, no acesso aos demais níveis de complexidade, na manutenção estrutural de equipamentos e no manejo de recursos disponíveis para a prática em saúde $e^{3-5}$.

Nos relatórios da Conferência Nacional de Recursos Humanos de 1986 a 1993 e na Norma Operacional Básica de Recursos Humanos (NOB/ $\mathrm{RH}$ ) para o Sistema Ú nico de Saúde(SU S) foram citadas preocupações a respeito deum perfil profissional não apropriado suficientemente para atuação em atenção integral à saúde ede práticas que visem à promoção, proteção, prevenção e reabilitação de doenças.
Em decorrência disto, o M inistério da Saúde, através do Departamento de Atenção Básica (DAB), criou os Pólos de Capacitação, Formação e Educação Permanente em Saúde da Família, cujo objetivo fora a integração ensino-serviço em torno de necessidades de capacitação dos profissionais de saú de da família. Adicionalmente, no ano 2000, o M inistério da Saúde convocou e repassou incentivos financeiros às universidades e escolas de saúde pública de todo o Brasil, com o objetivo das mesmas ofertarem cursos de graduação lato sensu, em especialização e residência multiprofissional em saúde da família. Estas medidas visaram então remodelar o perfil dos profissionais em saúde da família6,7.

A questão de recursos humanos representa desafios e riscos para a sustentabilidade deste programa. Desde a concepção do PSF, sabia-se da inexistência de profissionais com o perfil necessário para este novo modelo. Para atuarem em uma equipe de saúde da família, os profissionais precisam compreender a nova dinâmica do processo de trabalho. Para isso, é necessária uma visão ampliada, ser resolutível nas clínicas básicas e ser capaz de resolver pelo menos 80\% dos problemas de saúde da população em uma concepção de recuperação adequada de saúde e de qualidade de vida8-11.

É necessário conhecer as necessidades de cada profissional, para que cursos de capacitação e reciclagem de profissionais em serviço possam vir a adequar os perfis destes profissionai se consolidar a Estratégia Saúde da Família. Portanto, justifica-se a realização de pesquisas que visem monitorar a adequação do perfil dos profissionais de saúde em Programas de Saúde da Família em diferentes municípios do país.

Assim, está pesquisa teve como objetivo verificar asnecessidades de cada profissional da equipe de saúde da família no que tange à capacitação e aperfeiçoamento, visando analisar a adequação do perfil destes para a consolidação da Estratégia Saúde da Família.

\section{Metodologia}

Esta pesquisa tem características no paradigma empírico-analítico, sendo do tipo descritiva e qualiquantitativa.

A população estudada compreendeu 100\% dos profissionais de saúde dos Programas de Saúde da Família dos 31 municípios abrangidos pela 4a Coordenadoria Regional de Saúde do Estado do Rio Grande do Sul. Este estudo foi viável através de uma parceria entre o pesquisador e a 4a Coordenadoria Regional de Saúde. A divulgação e sensi bilização dos profissionais da Estratégia Saúde da Família foram possíveis devido a esta parceria. 
Para a coleta de dados, foram aplicados 682 questionários com questões fechadas (objetivas) com as seguintes variáveis: idade, sexo, experiências profissionais anteriores, pós-graduação, campo de competências (conjunto de saberes e de responsabilidades comuns a toda equipe) e núcleo de competências (conjunto de saberes e de responsabilidades específicos a cada profissão). 0 questionário foi composto de duas partes: a primeira, comum à toda equipe e a segunda, específica para cada categoria. N estes questionários, foram fornecidas opções de escolha em que o profissional poderia assinalar as tarefas mais fáceis até as mais difíceis, em um contínuo de escolhas. Os dados obtidos com a aplicação do questionário foram tratados com o método estatístico da normalidade (Shapiro-Wilk) para as categorias fáceis, intermediárias e difíceis, e os métodos do qui-quadrado e teste $\mathrm{G}$ (este quando o valor esperado era menor que 5) entre as categorias fáceis e difíceis. 0 teste da normalidade foi utilizado para se observar se dadas tarefas eram ou muito mais fáceis ou muito mais difíceis que o esperado (curva normal). 0 valor crítico para todos os testes estatísticos foi de 0,05. 0 programa estatístico utilizado foi o BioEstat $3.0^{12}$.

O projeto foi aprovado pelo Comitê de Ética e Pesquisa da Universidade Franciscana de Santa $M$ aria. Todos os aspectos éticos em conformidade com a Resolução no 196/96 do Ministério da Saúde foram respeitados, no que concerne o respeito à autonomia, não maleficência, beneficência ejustiça. Assim, foi preservada a integridade dos sujeitos objetos da pesquisa, buscando a maximização dos benefícios e minimização de danos e riscos, traçando um caminho ideal para o desenvolvimento da pesquisa, visando à relevância social e vantagens para os sujeitos da pesquisa. Foi explicado a cada profissional a metodologia do trabalho, e o termo de consentimento livre e esclarecido foi solicitado para legalizar sua aceitação e participação na pesquisa13 ${ }^{13}$.

\section{Resultados}

D os 682 questionários aplicados, foram devolvidos $460(67,5 \%)$, sendo que 51 destes estavam em branco. Do total de questionários devolvidos, 36 eram de médicos, 41, de enfermeiros, 66, deauxiliares deenfermagem, 22, de dentistas, 19, de auxiliares de consultório dentário e 225, de agentes comunitários de saúde.

Por faixa etária, 31\% dos médicos estão na faixa de 21 a 30 anos, sendo $72 \%$ do sexo masculino, 61\% com experiências anteriores na área de saúde da família e $25 \%$ são especialistas. Para dentistas da família, $41 \%$ estão na faixa etária de 21 a 30 anos, sendo metade do sexo masculino e $36 \%$ com experiências anteriores e especialização na área de saúde da família. A maioria dos enfermeiros da família também se encontra na faixa etária de 21 a 30 anos (44\%). 0 sexo predominanteéo feminino (98\%) e $61 \%$ possuem especialização na área de saúde da família. Entre os auxiliares de enfermagem, $55 \%$ se encontram na faixa etária de 21 a 30 anos, sendo 91\% do sexo feminino e $76 \%$ sem nenhuma formação na área de saúde da família. A maioria dos auxiliares de consultório dentário se encontra na faixa etária de 31 a 40 anos (32\%). A penas $16 \%$ destes são do sexo masculino e $79 \%$ não possuem nenhuma formação na área de saúde da família. Entre os agentes comunitários de saúde da família, 38,2\% se encontram na faixa etária de 31 a 40 anos (38\%). 0 sexo predominante neste grupo também é o feminino (89\%) e $65 \%$ não possuem nenhuma formação na área de saúde da família.

Com relação às atribuições para todas as equipes (médicos, enfermeiros, auxiliar de enfermagem, etc.), destacaram-se como fáceis as atribuições conhecimento da realidade das famílias (85\%), identificação dos problemas de saúde e situações de risco mais comuns (83\%), realização de visitas domiciliares conforme o planejamento da equipe (79\%), e criação do vínculo de confiança, de afeto e de respeito com o usuário e família (75\%). Como difíceis, destacaram-se as atribuições promoção de ações intersetoriais e parcerias com organizações formais e informais existentes na comunidade (81\%) e estimulação da participação popular na discussão sobre cidadania e direitos à saúde (77\%) (Tabela 1).

Com relação às atribuições específicas do médico, destacaram-se como fáceis as atribuições realização de consultas clínicas aos usuários da sua área adscrita (69\%) e relacionamento interpessoal com a equipe (44\%); como difícil, a atribuição conhecimento e preenchimento dos formulários do SIA/SIAB (42\%) (Tabela 2).

Com relação às atribuições específicas do enfermeiro, destacaram-se como fáceis as atribuições relacionamento interpessoal com a equipe (49\%) e como difíceis as atribuições realização de consulta de enfermagem, solicitação de exames complementares, prescrição/transcrição de medicações, conforme protocolos estabelecidos (49\%) e realização de cuidados diretos de enfermagem nas urgências e emergências clínicas (42\%) (Tabela 3).

Com relação às atribuições específicas do dentista, destacou-se como fácil a atribuição prescrição de medicamentos e outras orientações na conformidade dos diagnósticos efetuados (41\%) e como difíceis as atribuições encaminhamento e orientação dos usuários que apresentam problemas complexos a outros níveis de assistência, assegurando seu acompanhamento (41\%) e conhecimento epreenchimento dos formulários do SIA/SIAB (36\%) (Tabela 4). 
Com relação às atribuições específicas do auxiliar de enfermagem, destacou-se como fácil a atribuição realização de procedimentos de enfermagem dentro das suas competência técnicas e legais (82\%) e como difíceis as atribuições realização de busca ativa de casos, como tuberculose, hanseníasee demais doenças de cunho epidemiológico (67\%) econhecimento eprenchimento dos formulários do SIA/SIAB (62\%) (Tabela 5).

Com relação às atribuições específicas do auxiliar de consultório dentário, destacaram-se como fáceis as atribuições desinfecção e esterilização de materiais e instrumentos utilizados (68\%) e preparação e organização dos instrumentais e materiais (sugador, espelho, sonda, etc.) (68\%) e como difíceis as atribuições conhecimento e preenchimento dos formulários do SIA/SI AB (79\%) e acompanhamento edesenvolvimento de trabalhos com a equipe de saúde da família no tocante à saúde bucal (63\%) .

Com relação às atribuições específicas do agente comunitário de saúde, destacaram-se

Tabela 1. Facilidades e dificuldades dos profissionais de saú de da família, no que concerne às atribuições comuns a to das as equipes, dos municípios da abrangência da 4a Coordenadoria de Saúde, Santa M aria-RS, 2006.

\begin{tabular}{|c|c|c|c|}
\hline Atribuições comuns a toda equipe & $\begin{array}{c}\text { Fáceis } \\
\text { (N = } 3 \text { opções) }\end{array}$ & $\begin{array}{l}\text { Intermediárias } \\
\text { (N = } 1 \text { opção) }\end{array}$ & $\begin{array}{c}\text { Difíceis } \\
\text { ( } N=3 \text { opções) }\end{array}$ \\
\hline $\begin{array}{l}\text { Conhecimento da realidade das famílias de responsabilidade } \\
\text { da sua equipe: características sociais, econômicas, culturais, } \\
\text { demográficas e epidemiológicas. }\end{array}$ & $349(85,3 \%) *$ & $9(2,2 \%)$ & $30(7,3 \%)$ \\
\hline $\begin{array}{l}\text { Identificação dos problemas de saúde e situações de risco } \\
\text { mais comuns desta população. }\end{array}$ & $340(83,1 \%)^{*}$ & $27(6,6 \%)$ & $42(10,3 \%)$ \\
\hline $\begin{array}{l}\text { Elaboração do plano para enfrentamento dos problemas de } \\
\text { saúde local com a participação da comunidade. }\end{array}$ & $75(18,3 \%)$ & $164(40,1 \%)$ & $165(40,3 \%)$ \\
\hline $\begin{array}{l}\text { Criação do vínculo de confiança, de afeto e de respeito com } \\
\text { o usuário e família. }\end{array}$ & $305(74,6 \%)^{*}$ & $49(11,1 \%)$ & $40(9,8 \%)$ \\
\hline $\begin{array}{l}\text { Incentivo à formação e/ou participação ativa da comunidade } \\
\text { nos Conselhos Locais de Saúde e no Conselho M unicipal de } \\
\text { Saúde. }\end{array}$ & $55(13,4 \%)$ & $58(14,2)$ & $296(72,4 \%)$ \\
\hline $\begin{array}{l}\text { Estimulação da participação popular, discutindo com a } \\
\text { comunidade conceitos de cidadania, de direitos à saúde e } \\
\text { suas bases legais. }\end{array}$ & $43(10,5 \%)$ & $51(12,5 \%)$ & $315(77,0 \%) *$ \\
\hline $\begin{array}{l}\text { Promoção de ações intersetoriais e parcerias com } \\
\text { organizações formais e informais existentes na comunidade } \\
\text { para enfrentamento conjunto dos problemas identificados. }\end{array}$ & $33(8,0 \%)$ & $46(11,2 \%)$ & $330(80,7 \%) *$ \\
\hline $\begin{array}{l}\text { Execução de acordo com sua qualificação procedimentos de } \\
\text { vigilância sanitária e epidemiológica nas diferentes fases dos } \\
\text { ciclos de vida da população. }\end{array}$ & $84(20,5 \%)$ & $85(20,8 \%)$ & $240(58,7 \%)$ \\
\hline $\begin{array}{l}\text { Realização de visitas domiciliares conforme o planejamento } \\
\text { da equipe. }\end{array}$ & $322(78,7 \%)^{*}$ & $42(10,3 \%)$ & $45(11 \%)$ \\
\hline $\begin{array}{l}\text { Resolução dos problemas de saúde do nível de atenção } \\
\text { básica. }\end{array}$ & $211(51,6 \%)$ & $100(24,4 \%)$ & $98(24 \%)$ \\
\hline $\begin{array}{l}\text { Prestação de assistência integral à população da área de } \\
\text { abrangência respondendo a demanda de forma contínua e } \\
\text { racionalista. }\end{array}$ & $184(45 \%)$ & $114(27,9 \%)$ & $111(27,1 \%)$ \\
\hline $\begin{array}{l}\text { Garantia do acesso à continuidade do tratamento dentro do } \\
\text { sistema de referência e contra-referência para os casos de } \\
\text { maior complexidade }\end{array}$ & $60(14,7 \%)$ & $138(33,7 \%)$ & $211(51,6 \%)$ \\
\hline $\begin{array}{l}\text { Coordenação, participação e / ou organização de grupos de } \\
\text { educação para a saúde. }\end{array}$ & $158(38,6 \%)$ & $127(31 \%)$ & $124(30,3 \%)$ \\
\hline Participação na equipe multiprofissional e interdisciplinar. & $119(29 \%)$ & $134(32,8 \%)$ & $145(35,6 \%)$ \\
\hline Conhecimento, acesso e avaliação do SIAB. & $79(19,3 \%)$ & $67(16,4 \%)$ & $263(64,3 \%)$ \\
\hline
\end{tabular}

Normalidade: $N=15$; Fáceis: $P=0,0205$; Intermediárias: $P=0,487$; Difíceis: $P=0,2158$.

Qui-quadrado (entre fáceis e difíceis): $P=0,00001 ; G L=14 ; X^{2}=1919,2$.

${ }^{*}$ Atribuições significativas $(P<0,05)$ que foram mais citadas pelos profissionais. 
como fáceis as atribuições cadastramento das famílias e sua atualização permanentemente (80\%) ereal ização do mapeamento deárea (61\%) e como difíceis as atribuições identificação de parceiros e recursos existentes na comunidade que possam ser potencializados pela equipe (62\%), informação para a equipe de saúde da família da dinâmica social da comunidade, suas necessidades, potencialidades e limites (58\%) e promoção da educação ea mobilização comunitária, visando desenvolver ações coletivas de saneamento e melhoria do meio ambiente (56\%).

\section{Discussão}

0 presente estudo mostrou que as equipes de saúde da família dos municípios da 4a Coordenadoria Regional de Saúde são compostas por profissionais jovens, na sua maioria do sexo feminino. A maioria dos profissionais de nível superior possui experiência anterior em saúde da família, sendo a maioria especialista na área. 0 nível médio, na sua maioria, não possui formação na área de saúde da família. A falta de conhe- cimento nestaárea do pessoal denível médio pode levar à dificuldade do trabalho em equipe, uma vez que só o nível superior detém o conhecimento. 0 sucesso e resultado positivo do trabalho em equipe nesta estratégia, segundo M inistério da Saúde ${ }^{1}$, depende principalmente do perfil eda atuação de todos os profissionais envolvidos.

No campo de competências e atribuições comuns à toda equipe, a atribuição mais citada como fácil pelos profissionais de saúde da família foi a questão do conhecimento da realidade das famílias, além da identificação de problemas e riscos à saúde vinculada à família e criação de vínculo familiar. A facilidade em obter estes conhecimentos e vínculos se deve principalmente ao cadastramento realizado pelos agentes comunitários de saúde e também pelo fato dos mesmos, além de fazerem parte desta comunidade, desempenharem o papel de elo entre os profissionais de saúde e as famílias, trazendo e mostrando informações quefacilitam o trabalho das equipes. Outro fator importante pode ser a necessidade destetipo de serviço pelas famílias, quenormalmente são carentes, e também o nível adequado de formação e especialização dos profis-

Tabela 2. Facilidades e dificuldades dos profissionais de saúde da família no que concerne às atribuições específicas do M édico, dos municípios da abrangência da 4ạ Coordenadoria de Saúde, Santa M aria, RS, 2006.

\begin{tabular}{|c|c|c|c|}
\hline Atribuições específicas do médico & $\begin{array}{c}\text { Fáceis } \\
\text { ( } \mathrm{N}=3 \text { opções) }\end{array}$ & $\begin{array}{l}\text { Intermediárias } \\
\text { ( } N=8 \text { opções) }\end{array}$ & $\begin{array}{c}\text { Difíceis } \\
\text { ( } N=3 \text { opções) }\end{array}$ \\
\hline Realização de consultas clínicas aos usuários da sua área adscrita. & $25(69,4 \%) *$ & $7(19,4 \%)$ & $4(11,1 \%)$ \\
\hline $\begin{array}{l}\text { Execução das ações de assistência integral em todas as fases do } \\
\text { ciclo de vida criança, adolescente, mulher, adulto e idoso. }\end{array}$ & $9(25 \%)$ & $13(36,1 \%)$ & $8(22,2 \%)$ \\
\hline $\begin{array}{l}\text { Realização de procedimentos na Unidade de saúde e, quando } \\
\text { necessário, no domicílio. }\end{array}$ & $8(22,2 \%)$ & $21(58,3 \%)$ & $7(19,4 \%)$ \\
\hline $\begin{array}{l}\text { Realização de atividades clínicas correspondentes ás áreas } \\
\text { prioritárias na intervenção na atenção básica, definidas na } \\
\text { Norma O peracional da Assistência à Saúde-NOAS } 2001 .\end{array}$ & $9(25 \%)$ & $21(58,3 \%)$ & $6(16,7 \%)$ \\
\hline Aliar á atuação clínica à prática da saúde coletiva. & $7(19,4 \%)$ & $25(69,4 \%)$ & $4(11,1 \%)$ \\
\hline Organização e criação de grupos de educação em saúde. & $3(8,3 \%)$ & $20(55,6 \%)$ & $12(33,3 \%)$ \\
\hline $\begin{array}{l}\text { Realização do pronto atendimento médico nas urgências e } \\
\text { emergências. }\end{array}$ & $6(16,7 \%)$ & $20(55,6 \%)$ & $10(27,7 \%)$ \\
\hline $\begin{array}{l}\text { Encaminhamento aos serviços de maior complexidade, quando } \\
\text { necessário, garantindo a continuidade do tratamento na USF, } \\
\text { por meio de um sistema de acompanhamento, referência e } \\
\text { contra-referência. }\end{array}$ & $3(8,3 \%)$ & $19(52,8 \%)$ & $14(38,9 \%)$ \\
\hline Realização de pequenas cirurgias ambulatoriais. & $5(13,9 \%)$ & $26(72,2 \%)$ & $5(13,9 \%)$ \\
\hline Indicação de internação hospitalar. & $7(19,4 \%)$ & $25(69,4 \%)$ & $6(16,7 \%)$ \\
\hline Solicitação de exames complementares. & $7(19,4 \%)$ & $29(80,5 \%)$ & $2(5,6 \%)$ \\
\hline Verificar e atestar o óbito. & $3(8,3 \%)$ & $19(52,8 \%)$ & $14(38,9 \%)$ \\
\hline Relacionamento interpessoal com a equipe. & $16(44,4 \%)^{*}$ & $17(47,2 \%)$ & $3(8,3 \%)$ \\
\hline Conhecimento e preenchimento dos formulários do SIA/SIAB. & $0(0 \%)$ & $21(58,3 \%)$ & $15(41,7 \%)^{*}$ \\
\hline
\end{tabular}

Normalidade: $N=14$; Fáceis: $P=0,01$; Intermediárias: $P=0,4118$; Difíceis: $P=0,2454$.

Teste $G$ (entre fáceis e difíceis): $P=0,00001 ; G L=13 ; G=74,3$.

*Atribuições significativas $(P<0,05)$ que foram mais citadas pelos profissionais. 
sionais, já que muitos têm alguma experiência prévia com PSF. $O$ foco de atenção das equipes à família no seu espaço físico e social e o conhecimento da realidade delas irão proporcionar uma visão ampliada do processo saúde-doença, vivenciada pelas equipes de trabalho, norteando as equipes para uma maior facilidade no desenvolvimento de ações de promoção, prevenção, recuperação e reabilitação da saúde, conforme citado pelo M inistério da Saúde ${ }^{1}$.

A atividade mais difícil de desempenhar, segundo as equipes, é a questão das ações intersetoriais e parcerias com organizações existentes na sociedade. U ma vez que os diversos setores da sociedade sempre trabalharam de forma independente, as organizações formais e informais não estavam acostumadas a participar juntamente com profissionais de saúde no enfrentamento dos problemas de saúde das comunida- des onde as mesmas estão inseridas. Segundo o M inistério da Saúde 3 , o profissional de saúde da família deve ter habilidades ou desenvolver habilidades nas clínicas de estabelecimento de parcerias e trabal ho em equipe multissetorial.

No núcleo de competências de atividades específicas a cada profissão, a atividade citada como maisfácil pelos médicosfoi a realização de consultas aos usuários de sua área de abrangência. Isto se deve ao fato de que sua formação é toda baseada para este fim. A mais citada como difícil por estes profissionais foi a questão do conhecimento e preenchimento dos formulários do Sistema de Atenção Básica (SIAB). Esta dificuldade tem a ver, principalmente, com a questão cultural de que médicos e 0 ato de elaborar registros não se relacionam bem historicamente, cabendo aí um esforço por partedestes profissionais para compreender e preencher estes dados

Tabela 3. Facilidades e dificuldades dos profissionais de saúde da família no que concerne às atribuições específicas do Enfermeiro, dos municípios da abrangência da 4ạ Coordenadoria de Saúde, Santa M aria-RS, 2006.

\begin{tabular}{|c|c|c|c|}
\hline Atribuições específicas do enfermeiro & $\begin{array}{c}\text { Fáceis } \\
\text { (N = } 3 \text { opções) }\end{array}$ & $\begin{array}{l}\text { Intermediárias } \\
\text { ( } \mathrm{N}=7 \text { opções) }\end{array}$ & $\begin{array}{l}\text { Difíceis } \\
\text { ( } N=3 \text { opções })\end{array}$ \\
\hline $\begin{array}{l}\text { Realização de cuidados diretos de enfermagem nas urgências e } \\
\text { emergências clínicas, fazendo a indicação para a continuidade } \\
\text { da assistência prestada. }\end{array}$ & $6(14,6 \%)$ & $18(43,9 \%)$ & $17(41,5 \%) *$ \\
\hline $\begin{array}{l}\text { Realização de consulta de enfermagem, solicitação de exames } \\
\text { complementares, prescrição/transcriçãa de medicações, } \\
\text { conforme protocolos estabelecidos nos Programas do } \\
\text { M inistério da Saúde e as Disposições legais da profissão. }\end{array}$ & $11(26,8 \%)$ & $12(29,2 \%)$ & $18(43,9 \%) *$ \\
\hline $\begin{array}{l}\text { Planejamento, gerenciamento, coordenação, execução e } \\
\text { avaliação da U nidade de Saúde da Família. }\end{array}$ & $12(29,3 \%)$ & $25(61 \%)$ & $4(9,8 \%)$ \\
\hline $\begin{array}{l}\text { Execução de ações de assistência integral em todas as fases do } \\
\text { ciclo de vida: criança, adolescente, mulher, adulto e idoso. }\end{array}$ & $11(26,8 \%)$ & $17(41,5 \%)$ & $13(31,7 \%)$ \\
\hline $\begin{array}{l}\text { Realização de ações de saúde em diferentes ambientes, USF e, } \\
\text { quando necessário, no domicílio. }\end{array}$ & $8(19,5 \%)$ & $25(61 \%)$ & $8(19,5 \%)$ \\
\hline $\begin{array}{l}\text { Realização de atividades correspondentes ás áreas prioritárias na } \\
\text { intervenção na atenção básica, definidas na Norma } \\
\text { Operacional da Assistência à Saúde N NAS } 2001 .\end{array}$ & $4(9,8 \%)$ & $21(51,2 \%)$ & $15(36,6 \%)$ \\
\hline Aliar a atuação clínica à prática da saúde coletiva. & $2(4,9 \%)$ & $24(58,5 \%)$ & $13(31,7 \%)$ \\
\hline $\begin{array}{l}\text { Organização, coordenação e criação de grupos de educação em } \\
\text { saúde. }\end{array}$ & $11(26,8 \%)$ & $24(58,5 \%)$ & $6(14,6 \%)$ \\
\hline $\begin{array}{l}\text { Capacitação dos auxiliares de enfermagem e agentes } \\
\text { comunitários de saúde com vistas ao desempenho de suas } \\
\text { funções. }\end{array}$ & $7(17,0 \%)$ & $26(63,4 \%)$ & $8(19,5 \%)$ \\
\hline $\begin{array}{l}\text { Supervisão do desempenho dos agentes comunitários de saúde e } \\
\text { auxiliares de enfermagem. }\end{array}$ & $8(19,5 \%)$ & $33(80,5 \%)$ & $0(0 \%)$ \\
\hline $\begin{array}{l}\text { Coordenação das ações dos agentes comunitários de saúde e de } \\
\text { auxiliares de enfermagem. }\end{array}$ & $13(31,7 \%)$ & $26(63,4 \%)$ & $2(4,9 \%)$ \\
\hline Relacionamento interpessoal com a equipe. & $20(48,8 \%) *$ & $14(34,1)$ & $5(12,2 \%)$ \\
\hline Conhecimento e preenchimento dos formulários do SIA/SIAB. & $11(26,8 \%)$ & $20(48,8 \%)$ & $10(24,4 \%)$ \\
\hline
\end{tabular}

Normalidade: $N=13$; Fáceis: $P=0,5755$; $M$ édias: $P=0,7594$; Difíceis: $P=0,7606$.

Teste $G$ (entre fáceis e difíceis) $=60,4 ; G L=12 ; P=0,00001$.

*Atribuições significativas $(\mathrm{P}<0,05)$ que foram mais citadas pelos profissionais. 
que são necessários para avaliação do desempenho das equipes.

A atribuição mais citada como fácil pelos profissionais enfermeiros foi o relacionamento interpessoal com a equipe, o que talvez se deva ao fato do profissional de enfermagem, na sua formação, ser preparado para atuar em todos os campos da grande área de saúde, ser generalista, gerenciador de equipes e trabalhar em equipe multiprofissional. A mais difícil citada foi a realização de consulta de enfermagem, solicitação de exames e prescrição de medicamentos. Quanto a estas atividades citadas como difíceis, suas origens talvez estejam relacionadas à questão da sobrecarga de trabal ho deste profissional, que se ocupa mais de funções administrativas do que assistenciais. Também a limitação dos serviços de saúde que não estão utilizando plenamente o potencial deste profissional que, muitas vezes, desenvolve ações do pessoal de nível médio da enfermagem. A consulta de enfermagem é uma atividade exclusiva da competência deste profissional, amparado legalmente. A utilização deste recurso pelo enfermeiro propiciaria a diminuição da demanda reprimida, uma vez que todas as consultas são direcionadas ao profissional médico, dificultando assim o atendimento clínico ampliado, a concretização da universalidadee a vinculação do usuários a mais membros da equipe de saúde ${ }^{14}$.

A atividade citada como mais difícil pelos dentistas foi a questão do encaminhamento e orientação dos usuários com problemas complexos a outros níveis de assistência e assegurar 0

Tabela 4. Facilidades dos profissionais de saúde da família, no que concerne às atribuições específicas do Dentista, dos municípios da abrangência da 4ạ Coordenadoria de Saúde, Santa M aria-RS, 2006.

\begin{tabular}{|c|c|c|c|}
\hline Atribuições específicas do dentista & $\begin{array}{c}\text { Fáceis } \\
\text { (N = } 3 \text { opções) }\end{array}$ & $\begin{array}{l}\text { Intermediárias } \\
\text { (N = } 9 \text { opções) }\end{array}$ & $\begin{array}{l}\text { Difíceis } \\
\text { ( } N=3 \text { opções })\end{array}$ \\
\hline $\begin{array}{l}\text { Realização de levantamento epidemiológico para traçar o perfil } \\
\text { de saúde bucal da população adscrita. }\end{array}$ & $4(18,2 \%)$ & $10(45,5 \%)$ & $7(31,8 \%)$ \\
\hline $\begin{array}{l}\text { Realização de procedimentos clínicos definidos na Norma } \\
\text { Operacional Básica do Sistema Único de Saúde - NOB/SUS } 96 \\
\text { - e na Norma Operacional Básica da Assistência à Saúde } \\
\text { (NOAS). }\end{array}$ & $7(31,8 \%)$ & $10(45,5 \%)$ & $5(22,7 \%)$ \\
\hline $\begin{array}{l}\text { Realizar o tratamento integral, no âmbito da atenção básica } \\
\text { para a população adscrita. }\end{array}$ & $6(27,3 \%)$ & $11(50 \%)$ & $5(22,7 \%)$ \\
\hline $\begin{array}{l}\text { Encaminhamento e orientação dos usuários que apresentam } \\
\text { problemas complexos a outros níveis de assistência, assegurando } \\
\text { seu acompanhamento. }\end{array}$ & $4(18,2 \%)$ & $8(36,3 \%)$ & $9(40,9 \%)^{*}$ \\
\hline $\begin{array}{l}\text { Realização de atendimentos de primeiros cuidados nas } \\
\text { urgências. }\end{array}$ & $8(36,3 \%)$ & $11(50 \%)$ & $3(13,6 \%)$ \\
\hline Realização de pequenas cirurgias ambulatoriais. & $3(13,6 \%)$ & $13(59 \%)$ & $6(27,3 \%)$ \\
\hline $\begin{array}{l}\text { Prescrição de medicamentos e outras orientações na } \\
\text { conformidade dos diagnósticos efetuados. }\end{array}$ & $9(40,9 \%)^{*}$ & $12(54,5 \%)$ & $1(4,5 \%)$ \\
\hline $\begin{array}{l}\text { Emitir laudos, pareceres e atestados sobre assuntos de sua } \\
\text { competência. }\end{array}$ & $1(4,5 \%)$ & $19(86,4 \%)$ & $2(9,1 \%)$ \\
\hline $\begin{array}{l}\text { Execução de ações de assistência integral, aliado a atuação } \\
\text { clínica à saúde coletiva, assistindo as famílias, indivíduos ou } \\
\text { grupo específicos, de acordo com planejamento local. }\end{array}$ & $2(9,0 \%)$ & $14(63,6 \%)$ & $6(27,3 \%)$ \\
\hline $\begin{array}{l}\text { Coordenação de ações coletivas voltadas para promoção e } \\
\text { prevenção em saúde bucal }\end{array}$ & $5(22,7 \%)$ & $15(68,2 \%)$ & $2(9,1 \%)$ \\
\hline $\begin{array}{l}\text { Programação e supervisão do fornecimento de insumos para as } \\
\text { ações coletivas. }\end{array}$ & $0(0 \%)$ & $19(86,4 \%)$ & $1(4,5 \%)$ \\
\hline $\begin{array}{l}\text { Capacitação das equipes de saúde da família no que se refere às } \\
\text { ações educativas e preventivas em saúde bucal. }\end{array}$ & $3(13,6 \%)$ & $15(68,2 \%)$ & $4(18,2 \%)$ \\
\hline Supervisão do trabalho desenvolvido pelo ACD. & $6(27,3 \%)$ & $15(68,2 \%)$ & $1(4,5 \%)$ \\
\hline Relacionamento interpessoal com a equipe. & $4(18,2 \%)$ & $13(59,1 \%)$ & $4(18,2 \%)$ \\
\hline Conhecimento e preenchimento dos formulários do SIA/SIAB & $4(18,2 \%)$ & $9(41 \%)$ & $8(36,4 \%) *$ \\
\hline
\end{tabular}

Normalidade: $N=15$; Fáceis: $P=0,9259$; Intermediárias: $P=0,6189$; Difíceis: $P=0,4124$.

Teste $G$ (entrefáceis e difíceis): $P=0,0393 ; G L: 14 ; G=24,5$.

*Atribuições significativas $(P<0,05)$ que foram mais citadas pelos profissionais. 
seu acompanhamento. Talvez isto ocorra devido a uma limitação do sistema de saúde em que os mesmos estão inseridos e/ou porque não estão atuando como determinado pelas diretrizes do Sistema Ú nico deSaúde, deforma integral. A atividade mais fácil citada foi a prescrição de medicamentos e outras orientações aos usuários de sua área de abrangência, fato que está certamente relacionado à especialização destes profissionais na área específica de odontologia.

Para os profissionais auxiliares de enfermagem, a realização dos procedimentos de enfermagem dentro de suas competências técnicas e legais é a atividade mais fácil de ser executada. A atividade citada como mais difícil foi a busca ativa de casos de cunho epidemiológico. Esta dificuldade talvez se deva a uma fal ha na formação destes profissionais ena educação continuada no serviço onde os mesmos estão inseridos.

A atividade citada como mais difícil pelos auxiliares de consultório dentário foi o conhecimento e preenchimento dos formulários do SI A/ $S I A B$, evidenciando a falta de cursos de capacitação dentro da Estratégia de Saúde da Família para estes profissionais. As atividades maisfáceis citadas foram a preparação, organização, desinfecção e esterilização dos instrumentais e materiais odontológicos.
A atividade mais fácil citada pelos agentes comunitários de saúde foi o cadastramento das famílias e atualização permanente de cadastros. A atividade citada como mais difícil pelos agentes comunitários de saúde foi a identificação de parceiros e recursos existentes na comunidade que possam ser potencializados pela equipe. As dificuldades citadas pelos agentes comunitários de saúde evidenciam a falta de capacitação e treinamento em serviço destes profissionais.

\section{Conclusão}

Nesta pesquisa, foram abordados vários aspectos relacionados às facilidades e dificuldades em executar as atribuições, determinadas pelo $\mathrm{M} \mathrm{i-}$ nistério da Saúde, aos profissionais de saúde, na Estratégia Saúde da Família. Com relação às facilidades observadas, os profissionais mostraram menores dificuldades com atribuições genéricase relacionadas a métodos e técnicas básicas de cada área. Por outro lado, os resultados mostraram que, ainda após doze anos da criação desta estratégia, os profissionais encontram várias dificuldades em atuar da forma adequada e necessária a estenovo modelo detrabalho, o PSF. É necessário o conhecimento das necessidades detodosos pro-

Tabela 5. Facilidades dos profissionais de saúde da família no que concerne às atribuições específicas do Auxiliar de Enfermagem, dos municípios da abrangência da 4ạ Coordenadoria de Saúde, Santa M aria, RS, 2006.

\begin{tabular}{|c|c|c|c|}
\hline Atribuições específicas do auxiliar de enfermagem & $\begin{array}{c}\text { Fáceis } \\
\text { (N = } 3 \text { opções) }\end{array}$ & $\begin{array}{l}\text { Intermediárias } \\
\text { (N =9 opções) }\end{array}$ & $\begin{array}{l}\text { Difíceis } \\
\text { ( } N=3 \text { opções })\end{array}$ \\
\hline $\begin{array}{l}\text { Realização de procedimentos de enfermagem dentro das suas } \\
\text { competência técnicas e legais. }\end{array}$ & $54(81,8 \%) *$ & $7(10,6 \%)$ & $3(4,5 \%)$ \\
\hline $\begin{array}{l}\text { Realização de procedimentos de enfermagem nos diferentes } \\
\text { ambientes, U nidade de Saúde da família e nos domicílios, } \\
\text { dentro do planejamento deações traçados pela equipe. }\end{array}$ & $37(56 \%)$ & $17(25,8 \%)$ & $7(10,6 \%)$ \\
\hline $\begin{array}{l}\text { Preparar o usuário para consultas médicas e de enfermagem, } \\
\text { exames e tratamentos na USF. }\end{array}$ & $29(43,9 \%)$ & $25(37,9 \%)$ & $7(10,6 \%)$ \\
\hline $\begin{array}{l}\text { Zelar pela limpeza e ordem do material, de equipamento e de } \\
\text { dependências da USF, garantindo o controle de infecção. }\end{array}$ & $16(24,2 \%)$ & $30(45,5 \%)$ & $15(22,7 \%)$ \\
\hline $\begin{array}{l}\text { Realização de busca ativa de casos, como tuberculose, } \\
\text { hanseníase e demais doenças de cunho epidemiológico. }\end{array}$ & $6(9 \%)$ & $11(16,7 \%)$ & $44(66,7 \%)^{*}$ \\
\hline $\begin{array}{l}\text { No nível de sua competência, executar assistência básica e ações } \\
\text { de vigilância epidemiológica esanitária. }\end{array}$ & $8(12,1 \%)$ & $20(30,3 \%)$ & $33(50 \%)$ \\
\hline $\begin{array}{l}\text { Realizar ações de educação em saúdeaos grupos de patologias } \\
\text { específicas e às família de risco conforme planejamento da USF. }\end{array}$ & $9(13,6 \%)$ & $29(43,9 \%)$ & $23(34,8 \%)$ \\
\hline Relacionamento interpessoal com a equipe. & $19(28,8 \%)$ & $32(48,5 \%)$ & $9(13,6 \%)$ \\
\hline Conhecimento e preenchimento dos formulários do SI A/SIAB. & $9(13,6 \%)$ & $10(15,2 \%)$ & $41(62,1 \%)^{*}$ \\
\hline
\end{tabular}

Normalidade: $N=9$; Fáceis: $P=0,0933$; Intermediárias: $P=0,4152$; Difíceis: $P=0,2157$.

Qui-Quadrado (entre fáceis e difíceis) $=153,8 ; G L=8 ; P=0,00001$.

*Atribuições significativas $(P<0,05)$ que foram mais citadas pelos profissionais. 
fissionais que atuam nesta estratégia de trabal ho, para que os currículos universitários sejam adequados a este novo modelo, ecursos de capacitação e reciclagem sejam realizados pelo M inistério da Saúde, estado e municípios através dos Pólos de Capacitação eEducação Permanente para ampliar a visão destes profissionais e desenvolver habilidades que respondam às necessidades da comunidade da área adstrita e venham a adequar o perfil dos mesmos, para que esta estratégia em saúde seja consolidada.

\section{Colaboradores}

MEV Ferreira desenvolveu o presenteestudo. M D Schimith orientou o presente estudo. NC Cáceres auxiliou no tratamento estatístico do artigo.

\section{Referências}

1. Brasil. M inistério da Saúde. O CNS e a Construção do SUS: referências estratégicas para melhoria do modelo de atenção a saúde. Brasília: M inistério da Saúde; 2003.

2. Franco T, M erhy E. PSF-Contradições e Desafios. In: Conferência Nacional de Saúde; 1999; Campinas. [site da Internet] [acessado 2006 jan 09]. Disponível em: http://www.datasus.gov.br/cns/cns.htm

3. Brasil. M inistério da Saúde. Saúde da Família: panorama, avaliação e desafios. Brasília: Ministério da Saúde; 2005.

4. Brasil. Ministério da Saúde. Avaliação Normativa do Programa de Saúde da Família no Brasil: M onitoramento da implantação e funcionamento das equipes de saúde da família 2001-2002. Brasília: M inistério da Saúde; 2004.

5. Pierontoni CR. As Reformas do Estado, da Saúde e Recursos Humanos: limites e possibilidades. Cien Saude Colet 2001; 6(2):341-360.

6. Gil CRR. Formação de Recursos em Saúde da Família: paradoxos e perspectivas. Cad Saude Publica 2005; 21(2):490-498.

7. Teixeira CF, Sader NMB. Processo de Implementação dos Pólos de Capacitação, Formação e Educação Permanente para Profissionais de Saúde da Família. [site da Internet] 2005. [acessado 2005 out 11]. Disponível em: http://www.redeunida.org.br

8. Souza HM. Programa Saúde da Família. Rev Bras Enferm 2000; 53(Especial):3-4.

9. Brasil. Ministério da Saúde. Caminhos para a mudança da formação e desenvolvimento dos profissionais de saúde: diretrizes para a ação política para assegurar educação permanente no SUS. Brasília: Ministério da Saúde; 2003.

10. Faleiros JJ. Profissionais Para Reorientar o M odelo Assistencial. Quantos e Quais? Rev. bras. educ. med. 2001; 27(1):55-64. 
11. Nogueira RP, organizador. Avaliação das tendências e prioridades sobre recursos humanos da saúde. [site da Internet] [acessado 2005 set 10]. Disponível em: http:/ /www.observatorio.nesc.ufrn.br/quem t01.htm

12. Ayres M, Ayres Jr RM, Ayres DL, Santos AS. BioEstat 3.0. A plicações estatísticas nas áreas das Ciências Biológicas e M édicas. Belém: Sociedade Civil M amirauá; 2003.

13. Conselho Nacional de Saúde. Resolução no 196/ 196, de 10 de outubro de 1996. Dispõe sobre pesquisa envolvendo seres humanos. Diário Oficial da União 1996; 16 out.

14. Schimith MD, Lima MADS. Acolhimento e vínculo em uma equipe do Programa de Saúde da Família. Cad Saude Publica 2004; 20(6):1487-1494.

Artigo apresentado em 02/09/2007

Aprovado em 14/12/2007

Versão final apresentada em 31/03/2008 